\title{
THE GULLSTRAND GOLD MEDAL OF THE SWEDISH MEDICAL SOCIETY
}

THIs medal was instituted in honour of the late Professor Gullstrand in 1922. There has been no award since that date. It is with the greatest pleasure we announce that this medal has now been awarded to Professor Priestley Smith for his "Ophthalmological researches, especially regarding glaucoma and the permanent growth of the lens." Few ophthalmologists of his generation in the world, and none in Britain, have done more brilliant work than Professor Priestley Smith. The Gullstrand Gold Medal is an honour primarily to the recipient and through him to British Ophthalmology and we are sure that all in this country and indeed all over the world will wish to associate themselves with us in congratulating the veteran Priestley Smith upon this recognition of his life's work.

\section{ABSTRACTS}

\section{I.-PATHOLOGY}

(1) Chapman, Vernon A. (Milwaukee, Wisconsin).-A case of melanoma of the caruncle. Amer. Jl. of Cancer, Vol. XVI, No. 3, May, 1932.

(1) Chapman records a case which occurred in a farmer, aged 58 years, who was seen in November, 1924. Four years before a small black spot had arisen at the inner corner of the left eye. It increased in size, gradually at first, and more rapidly during the last year. No history of injury was obtained. The illustration shows a triangular intensely black, lobulated tumour of the caruncle extending downwards and outwards between the globe and the lower lid; it was not attached to the sclera. The lid margins in apposition showed early infiltration with brown pigment. Under general anaesthesia the growth was removed by block dissection, with the inner third of each eyelid, the skin of the nose on that side and the fat from the inner quadrant of the orbit. Ten glass radon seeds of 0.5 millicurie each were implanted in the tissue about the site of the tumour. The patient made an uninterrupted recovery and when seen, in August, 1931, there was no sign of recurrence.

The pathological report was "spindle-celled melanoma of the eye." 
Four excellent microphotographs illustrate the histology of the growth. The author comments on the comparative benignity of the tumour in this instance.

R. R. J.

(2) Baquis (Florence).-Further contribution to the study of tumours of the reticulo-endothelial system; reticuloma of the orbit. (Ulteriore contributo allo studio del tumori del sistema reticolo endoteliale; reticuloma del orbita). Lett. Oftal., April, 1932.

(2) Baquis gives the history of a case of orbital tumour which he was able to follow from an early stage to the end. The subject was a boy, aged 10 years; a swelling had been noticed in the right upper lid for some three weeks. The growth increased very rapidly. After application of radium, the mass disappeared but recurred after a short interval. Further application of radium again caused shrinking of the mass, of which a part had been excised and examined, proving to be a round celled sarcoma; the parents would not permit at this time any surgical interference, but after further relapse the orbit was emptied. At the operation the whole orbit was found to be filled by new growth, which was not in any place adherent to the bone. Further relapse occurred and the boy died with cerebral complications, 18 months after the first appearance. Baquis discusses the nature of the growth and decides that it was a primary sarcoma of the reticulo-endothelial system, and probably of the same nature as "Ewing's sarcoma." This has never previously been met with in this situation.

The points in favour of this, are the reaction to radium, the absence of metastases, the soft consistency and slight fever, which led the family doctor to mistake the last recurrence for an abscess and to incise it.

- Harold Grimsdale.

(3) MacMillan, J. A. (Montreal).-On the origin and disposition of the cells in endophthalmitis. Trans. Amer. Ophthal. Soc., Vol. XXIX, p. 444. 1931.

(3) MacMillan has made slit-lamp investigations and a histological study of 70 cases of endophthalmitis, with the object of demonstrating the distinctive linear arrangement of the cells in this disease. This phenomenon is not seen in severe or long standing cases.

Large deposits of leucocytes are to be seen on the orbiculus ciliaris just in front of the ora serrata for a distance of 1-2 mm. and from this they take two main paths, one into the interior of the vitreous in the direction of its centre and the other backwards along the retina with offshoots into the vitreous. 
Another mass of cells is situated $1 \mathrm{~mm}$. in front of the one described above; and from this lines of cellular extension pass over the zonula and posterior aspect of the lens to be continuous with the same linear extension on the opposite side.

In the posterior part of the globe the cells lying free in the vitreous are disposed in irregular and ill-defined banks and some are heaped up on the retina in the vicinity of a blood vessel. It is probable that the cells migrate along the vitreous fibres. MacMillan quotes Salzmann's account of the structure of the vitreous and points out the similarity between the linear arrangement of cells in endophthalmitis and the disposition of the fibre structure of the vitreous. He suggests that the vitreous fibres guide the cells after their escape into the vitreous.

MacMillan stresses the importance of the anterior border layer of the vitreous in delimiting cellular migration and influencing the clinical picture in endophthalmitis and iridocyclitis.

The cells are mainly polymorphonuclear leucocytes and come from that portion of the ciliary body to which the base of the vitreous is attached and from the retinal vessels. The cells which invade the anterior segment of the eve come from the anterior portion of the orbiculus ciliaris, corona ciliaris and iris. In severe infections involving both the anterior and posterior segments the iris, ciliary body and retina supply the cells.

\section{H. B. StallaRd.}

\section{(4) Samuels, Bernard (New York).-Some notes on orbital tumours. Arch. of Ophthal., June, 1932.}

(4) Much has been written about the morphology of orbital tumours and Samuels in this paper, concerns himself more with the manner in which the pre-existing orbital structures react to the presence of a neoplasm. Carcinoma cells in their metabolism produce an intensely irritating toxin which brings about lymphocytic infiltration of the adjoining tissues with the result that bands of connective tissue are formed which impede the growth of the tumour. These bands, by their contraction, may draw the eyeball to one side and fix it to the wall of the orbit. Cylindromas usually derived from the lacrymal gland and resembling basal celled carcinoma are not so irritating, though there may be a good deal of fibrosis associated with them, also glaucoma may occur in these cases, as a result of interference with venous outflow. Sarcoma, in contrast to carcinoma, produces few signs of inflammation in the surrounding tissue. Though definitely malignant, this tumour often appears to have a capsule. The growth may indent the sclera without perforating it and so may bring about an intra-ocular appearance simulating retinal detachment. Haemangiomata are rare in the orbit but dangerous because of their 
tendency to enlarge and to cause pressure atrophy of the orbital contents and even of the bony wall. Neurofibromatosis, especially in the apex of the orbit may bring about early reduction of vision by pressure on the optic nerve. A contrast is afforded by glioma of the optic nerve in which vision may be preserved for an indefinite time. The absence of pain in most neoplasms of the orbit, is probably due to the easy displacement forward of the eye. Intraocular sarcoma provides a contrast to carcinoma in that the irritation it produces is due to a toxin developed as a result of necrosis of its constituent cells, whereas, in carcinoma, the toxin is produced by the living cells. Purulent necrosis of the sclera may occur beneath a choroidal sarcoma and allow of its extension to the orbit. Samuels' article concludes with a short account of the difficulties in diagnosis of inflammatory pseudo-tumour of the orbit and a warning against exenteration being performed without excluding a syphilitic or other inflammatory cause for the proptosis.

\section{F. A. W-N.}

\section{II.-LENS}

(1) Kirby, Daniel B. (New York).-Calcium in relation to cataract. Arch. of Ophthal., June, 1931.

(1) Kirby's examination of the literature on this subject reveals the following :-

1. That calcium decreases the permeability of the lens capsule which normally acts as an inert semi-permeable membrane. A slight reduction in the permeability of the lens capsule will obstruct the metabolic processes of the lens sufficiently to cause cataract. 2. That solutions of calcium salts have no action on fresh animal lenses in vitro except in concentration far beyond the physiological range. 3. Lenses unaffected by ultra-violet light can be rendered opaque by this means if previously sensitised with calcium chloride in a concentration which by itself is too weak to cause any changes. 4. The excess of calcium found in cataractous lenses is a secondary phenomenon and is not the primary cause of senile cataract. 5. The primary change is probably breaking down of the complicated colloidal solution of lens protein with extrusion of a molecule of water. 6. Calcium is of importance in stabilising any colloidal solution.

With these considerations in mind Kirby investigated the effect of varying concentrations of calcium on the growth of lens epithelial cells in vitro. Six separate cultures were used in each experiment of which three were controls. These experiments 
showed that the cells would withstand relatively large increase in the calcium content of the culture medium but that slight reduction below the optimum amount produced toxic reactions. It is known from the experiments of Burge and others that a cataractous lens contains 12 times as much calcium and about a quarter as much potassium as does the normal one. The next question to decide therefore was the effect of altering the calcium and potassium content of the culture medium in which the lens epithelial cells were being grown. Increase of the potassium content produced no effect, and although that of an absolute decrease in potassium content is not reported, a relative decrease, i.e., by increasing the calcium content produced no harmful effect either.

With regard to cataract in vivo, there seems to be an undoubted relationship between calcium deficiency and parathyroid cataract, but in senile cataract there is no evidence of any such relationship. In the first place the serum of patients with cataract contained the normal or possibly a little more than the normal amount of calcium and secondly, elaborate dietetic experiments (giving acid and alkaline diets and measuring the total intake and excretion of calcium) showed that patients with cataract responded normally to the factors influencing calcium metabolism and were utilising the element in the proper manner. The author can therefore see no indication for the administration of parathyroid to patients suffering from senile cataract.

(2) Evans, Everette I. and Keen, Ruth (Chicago). The relation of the parathyroid gland to cataract. Amer. Jl. of Ophthal., October, 1931.

(2) Evans and Keen having been struck by the possible association of parathyroid dysfunction and the production of senile cataract decided to analyse the lenses in dogs which had been rendered cataractous by thyroid-parathyroidectomy. During the survival period after operation the blood calcium was low while the calcium content of the cataractous lens was about 25 times the normal. On the other hand the inorganic phosphorous content of the blood was raised, while there was no significant alteration in the phosphorous content of the lens. The similarity between the changes in mineral content of lenses which have becomeataractous as a result of senility and of parathyroidectomy leads the authors to the conclusion that "in some obscure manner" the cause "may be substantially the same in each case" and that "serious notice should be taken of the rôle of the glands (the parathyroids) in the maintenance of normal conditions of the lens proteins." Their results also show that the production of parathyroid cataract is in no direct way dependent on the calcium content of the blood.

F. A. W-N. 


\section{III.-MISCELLANEOUS}

(1) Giraudi, Gioffredo (Rome).-The syndrome of tumours of the apex of the petrous bone. Revista Oto-Neuro-Oftal., January-February, 1931.

(1) Though primarily of oto-laryngological interest this syndrome concerns the ophthalmologist, since the extra-ocular muscles may be implicated. The primary growth is usually a malignant neoplasm of the nasopharynx and the symptoms may be considered under three headings:-(1) Auricular, comprising catarrhal or purulent myringitis and otitis; (2) Trigeminal, caused by invasion of the cavum Meckellii, with resulting corneal anaesthesia and signs due to invasion of the other branches of the fifth nerve. The sympathetic root is sometimes involved also, causing slight ptosis and contraction of the pupil. (3) Abducens, due to invasion of this nerve, bringing about paresis, or more commonly, paralysis of the external rectus. The inferior portions of the apex of the petrous bone are usually destroyed and prognosis is bad, though radiological treatment may bring about clinical improvement and diminution of pain.

\section{F. A. W-N.}

(2) Ferrer, Horacio (Havana, Cuba).-Diffuse hyperostosis of the sphenoid with great enlargement of the anterior clinoid processes: ocular manifestation. Amer. Jl. of Ophthal., May, 1931.

(2) Ferrer's case is of interest, both on account of its rarity and of the difficulty in diagnosis. The patient was a woman who had had defective sight in the right eye since girlhood. The defect had become gradually worse and vision, when seen, was reduced to counting fingers at two feet. The left optic disc was pale and slightly cupped, the vessels being rather distended on the nasal side. The left fundus showed some pallor of the temporal half of the disc, but was otherwise normal. There was a definite increase of the right intra-ocular pressure which increase disappeared under miotics. The peripheral fields were normal but there was a central scotoma for colours in the right eye. Investigations as to cause proved negative until an X-ray was taken of the skull which revealed hyperostosis of the body of the sphenoid and its wings with considerable enlargement of the anterior clinoid processes. The enlargement of this bone had produced a pressure atrophy of the right optic nerve, but curiously enough none of the other cranial nerves showed any evidence of injury.

$$
\text { F. A. W-N. }
$$


(3) Lewis, Park (Buffalo, N.Y.).-Cataract in the eyes of freshwater fishes, due to the invasion of the larvae of trematoid worms. Trans. Thirty-sixth Annual Meeting, Amer. Acad. of Ophthal. and Oto-Laryngol., French Lick, Ind., pp. 143-158, September 13-19, 1931.

(3) Park Lewis had the opportunity of studying in the Aquarium of the Buffalo Society of Natural Sciences a number of trout of all ages suffering from cataract. He found in the posterior portion of the cortex under the capsule a number of small objects in motion which proved to be the larvae of a trematoid worm of the fluke variety. A similar condition had been noted by Nordmann as early as 1832, and had been verified by other observers in perch and pike. The life history of this fluke is that the host in which the eggs are produced is ordinarily a vertebrate and in the case of the strigeidae (which is the fluke found in the fish's eye), the vertebrate is usually a bird such as a duck. Mature eggs from the bird pass into the pond and the active embryo takes up its residence in water snails and forms cysts. These sporocysts burst and migrate into the tissue of the snail, ultimately escaping through the body wall of the host, swim about in the water and, meeting a fish, penetrate the skin and get into the eye and after a time cause cataractous changes.

The reviewer has examined a number of fish with the ophthalmoscope. Cataract is common amongst fish which have been kept in an aquarium, although not very common in fresh water fish which live in streams. The cataract is seldom mature and therefore probably not due to the fluke. Opacity of the lens normally occurs very rapidly after any fish have been taken out of water.

$$
\text { M. S. MAYOU. }
$$

(4) Powell, Lyle S. (Lawrence, Kansas). - Herpes zoster ophthalmicus. Amer. Jl. of Ophthal., September, 1930.

(4) Powell's paper opens with quotations from various workers. Thus: Teague, Goodpasture and Lipschutz state that herpes zoster is due to a virus "differing from the virus herpes simplex only in virulence" and Hunt "that the spinal fluid in this disease shows a marked increase of lymphocytes," Metz "that total ophthalmoplegia may occur" and Fuchs "that facial paralysis may also occur." Corneal anaesthesia or ulcerative involvement, with possible destruction of the eye, ptosis, mydriasis or cycloplegia may all be associated with herpes zoster ophthalmicus. Powell's own case showed deep corneal inflammation and paralysis of the seventh, ninth and tenth nerves-involvement of the latter two nerves being indicated by loss of taste on the posterior third of the 
tongue, anaesthesia of the palate and pharynx and weakened response of the right vocal cord on phonation. There was also a low grade of uveitis in the affected eye.

$$
\text { F. A. W-N. }
$$

\section{(5) Mayer, Leo. L. (Chicago). - The vitreous in experimental detachment of the retina. Arch. of Ophthal., June, 1932.}

(5) Mayer's paper is in the nature of a preliminary communication concerning work which may have an important bearing on the pathology of retinal detachment. In the first place, the author refers to a previous paper (Arch. of Ophthal. Vol. 7, pp. 449, April, 1932) concerning a mechanical method of artificially detaching the retina. The result of using this method was that although a hole was produced in the retina spontaneous reattachment occurred after 6 weeks. The author therefore felt that some other factor must also be at work, possibly in the vitreous itself, so he tried the effect of injecting 3 minims of a 1 in 4 dilution of saturated trypsin solution in normal saline. The result was to bring about a prolonged detachment of the retina which nevertheless was not permanent. Investigation of the vitreous in eyes thus treated showed an enormous increase in sugar content, an increase in total nitrogen and an increase in surface tension, while there was a decrease in amino nitrogen and hydrogen ion concentration towards the acid side.

$$
\text { F. A. W-N. }
$$

(6) Abraham, V. Samuel.-Anterior chamber punctures in relation to intra-ocular tension. Arch. of Ophthal., June, 1932.

(6) It seems at first sight a logical proceeding in cases of raised intra-ocular pressure to puncture the anterior chamber, allow the escape of aqueous and so bring about a reduction of pressure. Unfortunately, for the success of this proceeding, a reactive hyperaemia occurs in the ciliary body and uveal tract generally, which may bring about a rise in intra-ocular pressure and result in the formation of new aqueous with a high protein content. On the other hand, hypotonia may occur in an eye whose function is subnormal or whose ciliary body has been paralysed by atropine. In primary and secondary glaucoma the results are variable, some cases showing a higher pressure after anterior chamber puncture while in others it is unaffected or may be reduced. Abraham's paper gives details of 9 cases illustrating these points.

$$
\text { F. A. W-N. }
$$

